\title{
Reference gene alternatives to Gapdh in rodent and human heart failure gene expression studies
}

Trond Brattelid ${ }^{2,3,5}$, Lisbeth H Winer ${ }^{1,3}$, Finn Olav Levy ${ }^{2,3}$, Knut Liestøl ${ }^{4}$, Ole M Sejersted ${ }^{1,3}$, Kristin B Andersson ${ }^{1,3^{*}}$

\begin{abstract}
Background: Quantitative real-time RT-PCR (RT-qPCR) is a highly sensitive method for mRNA quantification, but requires invariant expression of the chosen reference gene(s). In pathological myocardium, there is limited information on suitable reference genes other than the commonly used Gapdh mRNA and 185 ribosomal RNA. Our aim was to evaluate and identify suitable reference genes in human failing myocardium, in rat and mouse postmyocardial infarction (post-MI) heart failure and across developmental stages in fetal and neonatal rat myocardium.

Results: The abundance of Arbp, Rpl32, Rpl4, Tbp, Polr2a, Hprt1, Pgk1, Ppia and Gapdh mRNA and 18S ribosomal RNA in myocardial samples was quantified by RT-qPCR. The expression variability of these transcripts was evaluated by the geNorm and Normfinder algorithms and by a variance component analysis method. Biological variability was a greater contributor to sample variability than either repeated reverse transcription or PCR reactions.

Conclusions: The most stable reference genes were Rp/32, Gapdh and Polr2a in mouse post-infarction heart failure, Polr2a, Rp/32 and Tbp in rat post-infarction heart failure and Rp/32 and Pgk1 in human heart failure (ischemic disease and cardiomyopathy). The overall most stable reference genes across all three species was Rpl32 and Polr2a. In rat myocardium, all reference genes tested showed substantial variation with developmental stage, with Rp/4 as was most stable among the tested genes.
\end{abstract}

\section{Background}

Quantification of mRNA abundance is a central tool in studying pathological and compensatory mechanisms in heart failure. Quantitative real-time RT-PCR (RT-qPCR) has rapidly replaced other methods, allowing quantification of many gene transcripts in limited tissue samples and more sensitive detection of weakly expressed transcripts [1]. However, this level of sensitivity requires a careful choice of method for comparison of expression data between samples. The most common strategy is to normalize the expression of a specific gene to a single reference gene, assuming that the reference gene expression is invariant between the compared physiological states. Variation in the reference gene expression between samples would therefore reflect variations in sample preparation and experimental variability. Several studies have concluded that it is difficult to identify general reference genes which can be used in all

\footnotetext{
* Correspondence: k.b.andersson@medisin.uio.no
'Institute for Experimental Medical Research, Oslo University Hospital Ullevål,

* Correspondence: k.b.andersson@medisin.uio.no
${ }^{1}$ Institute for Experimental Medical Research, Oslo University Hospital Ullevål, Oslo, Norway
}

(c) 2010 Brattelid et al; licensee BioMed Central Ltd. This is an Open Access article distributed under the terms of the Creative Commons Attribution License (http://creativecommons.org/licenses/by/2.0), which permits unrestricted use, distribution, and reproduction in any medium, provided the original work is properly cited. reference gene(s) is important for each experimental setting [2-5].

In the heart failure literature, glyceraldehyde 3-phosphate dehydrogenase (Gapdh) and $18 S$ ribosomal RNA are the most frequently used reference genes in quantification of gene expression, see e.g. [6-8]. In rat neonatal cardiomyocytes, it was shown that Gapdh expression was invariant with different hypertrophic stimuli [9], but was decreased in electrically stimulated cells [10]. In a recent rat post-myocardial infarction (post-MI) heart failure study, the interpretation of changes in gene expression was dependent on the choice of Gapdh or $18 S$ as reference gene [11]. Only one recent study has examined possible reference gene candidates in human myocardium by mining public microarray data [12].

The aim of our study was to identify alternative reference genes to Gapdh and $18 S$ rRNA for use in mouse and rat post-myocardial infarction heart failure models and in human heart failure studies. Since fetal and neonatal rat cardiomyocytes are commonly used in cardiac hypertrophy and signal transduction experiments, we 
also evaluated a subset of candidate reference genes in neonatal and embryonic myocardium in comparison to adult myocardium. In addition we have investigated the sources of variation in gene expression quantification data in terms of RNA preparation methods, technical replicates and biological sample variability.

\section{Results}

\section{Total RNA sample quality}

Each total RNA sample was evaluated extensively by optical density, RNA profiling (Bioanalyzer) (Table 1) and the linearity of $18 \mathrm{~S}$ serial dilution curves (data not shown). The $260 \mathrm{~nm} / 280 \mathrm{~nm}$ optical density (O.D.) ratios for rodent and human total RNA samples were similar regardless of isolation method, with no difference between the groups within each species (Table 1). The 28S/18S area ratios were consistently low (1.3), but the RNA Integrity Number (RIN) values were consistent and comparable within each species and group: Sham versus myocardial infarction (MI) or non-failing versus failing, with an overall average of 8.0.

\section{Interspecies variation in reference gene expression}

The candidate genes Arb, Rpl32, Rpl4, Tbp, Polr2a, Hprt1, Pgk1, Ppia for each species and $18 S$ ribosomal RNA were quantified by RT-qPCR. Due to the dominance of $18 S$ transcripts compared to the other reference genes of interest, the $18 \mathrm{~S}$ data were used only as a control of the RT reaction in addition to the RNA quality control (dilution curve linearity). In mouse hearts, the post-MI/Sham ratio for $18 \mathrm{~S}$ was significantly higher than one (ratio 1.47, 95\% CI: [1.19-1.82]). In rat hearts the $18 S$ post-MI/Sham ratio was also above one, but with borderline significance (ratio 1.58, [1.00-2.51]). In the human myocardium there was no significant difference (failing/non-failing ratio 1.19, [0.76-1.84]).

The overall variability in the relative abundance for each reference gene and sample group, MI/Sham (mouse and rat) or non-failing/failing (human) is shown in Figure 1. The mean assay coefficient of variation (CV) for each species was 8,22 and $25 \%$ for mouse, rat and human, respectively. We next estimated the factors contributing to the gene expression variability by a variance component analysis method (see Methods). For mice, the relative size of the variance components for triplicate PCR reactions, RT repeats and biological samples were 1:1:4. The corresponding relative variance components for rat and human myocardium were 1:5:20 and 1:1:12, respectively. Overall, the biological samples, rather than sample preparation or technical replicates, contributed the most to the gene expression variability.

We found that gene expression variability was low for most of the analyzed reference genes. However, Ppia was highly variable in mice as was Gapdh in humans, whereas $A r b p$ was moderately to highly variable in all species. In general, there was good correlation between the stability values generated by the geNorm and Normfinder algorithms for all three species (Figure 2), and by the variance component analysis (data not shown). The overall rank order of the most stable reference for each species is shown in Table 2, taking into account the results from the geNorm, Normfinder and the variance component analysis models. Stable candidate reference genes include $R p l 32$, which obtained low variability scores in all three species. The variability score for Polr2a was low in mouse and rat (Figure 2). However, human Polr $2 a$ was among the more variable genes according to both geNorm and Normfinder, while visual inspection (Figure 1C) and the variance component analysis suggested low variablity also in humans. This inconsistency may have a methodological explanation, see the discussion.

To test the robustness of our findings, we evaluated the stability of a subset of reference genes in a second independent set of rat total RNA from Sham and postMI myocardium (dataset 2). The samples prepared for dataset 2 differed in sample storage (dataset 1, - 80C freezer; dataset 2, RNALater), RNA isolation (dataset 1, homogenizer and Trizol; dataset 2 , bead mill and Trizol) and cDNA priming methods (dataset 1, random hexamer; dataset 2, oligo-dT). Comparison of the same genes for datasets 1 and 2 yielded a nearly identical

Table 1 Quality evaluation of total RNA samples

\begin{tabular}{|c|c|c|c|c|c|c|c|c|c|c|c|}
\hline & & \multirow[b]{2}{*}{$\mathbf{n}$} & \multicolumn{3}{|c|}{ OD $260 \mathrm{~nm} / 280 \mathrm{~nm}$} & \multicolumn{3}{|c|}{$28 \mathrm{~S} / 18 \mathrm{~S}$ area ratio } & \multicolumn{3}{|c|}{ RNA integrity number (RIN) } \\
\hline & & & Mean & SD & CV (\%) & Mean & SD & CV (\%) & Mean & SD & CV (\%) \\
\hline \multirow[t]{2}{*}{ Mouse } & Sham & 3 & 2.05 & 0.01 & 0.2 & 1.23 & 0.12 & 9.3 & 7.9 & 0.2 & 1.9 \\
\hline & $\mathrm{Ml}$ & 3 & 2.06 & 0.01 & 0.5 & 1.33 & 0.06 & 4.4 & 8.2 & 0.3 & 3.2 \\
\hline \multirow[t]{2}{*}{ Rat } & Sham & 3 & 2.03 & 0.01 & 0.5 & 1.40 & 0.10 & 7.1 & 8.8 & 0.3 & 3.0 \\
\hline & $\mathrm{Ml}$ & 3 & 2.05 & 0.01 & 0.3 & 1.50 & 0.00 & 0.0 & 8.5 & 1.4 & 16.5 \\
\hline \multirow[t]{2}{*}{ Human } & Donor & 4 & 2.03 & 0.03 & 1.3 & 1.36 & 0.36 & 26.5 & 7.2 & 1.9 & 26.0 \\
\hline & Failing & 6 & 2.01 & 0.03 & 1.3 & 1.07 & 0.23 & 21.5 & 7.6 & 0.3 & 3.8 \\
\hline
\end{tabular}



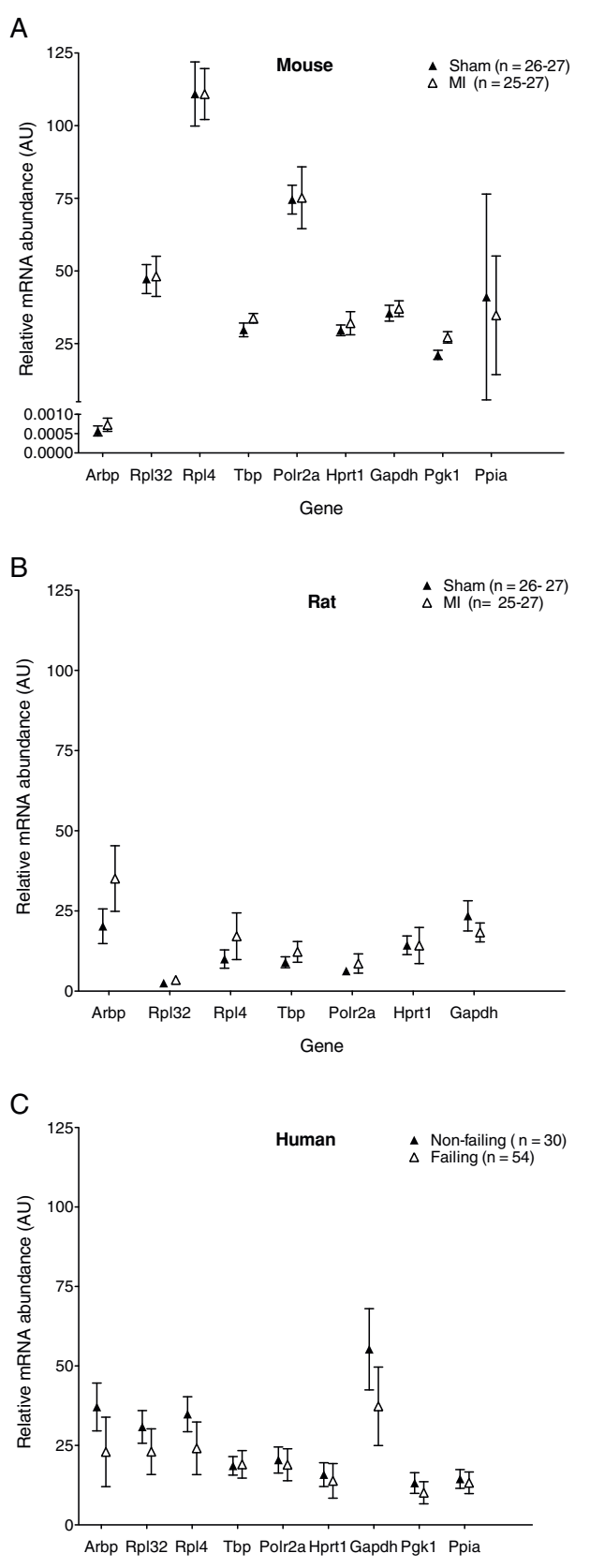

Gene

Figure 1 Variation in candidate reference gene abundance in mouse, rat and human myocardium. The indicated speciesspecific assays were run and $\mathrm{Cq}$ values converted to relative mRNA quantities (arbitrary units) using standard curves generated from species-specific pooled samples. To illustrate the total variability in the datasets for each species, the plotted data points (mean \pm SD) includes all PCR runs generated from all biological samples and RT repetitions within the sham/Ml or donor/failing groups for each gene. For mouse and rat groups, $n=$ maximum of 27 PCR reactions within each group for all tested genes. For human genes, $n=30$ $P C R$ reactions were included in the donor group and 54 PCR reactions in the failing group for each gene, respectively. (A) mouse Sham and post-Ml samples; (B) rat Sham and post-Ml samples and (C) human non-failing (donor) and failing heart samples.
A
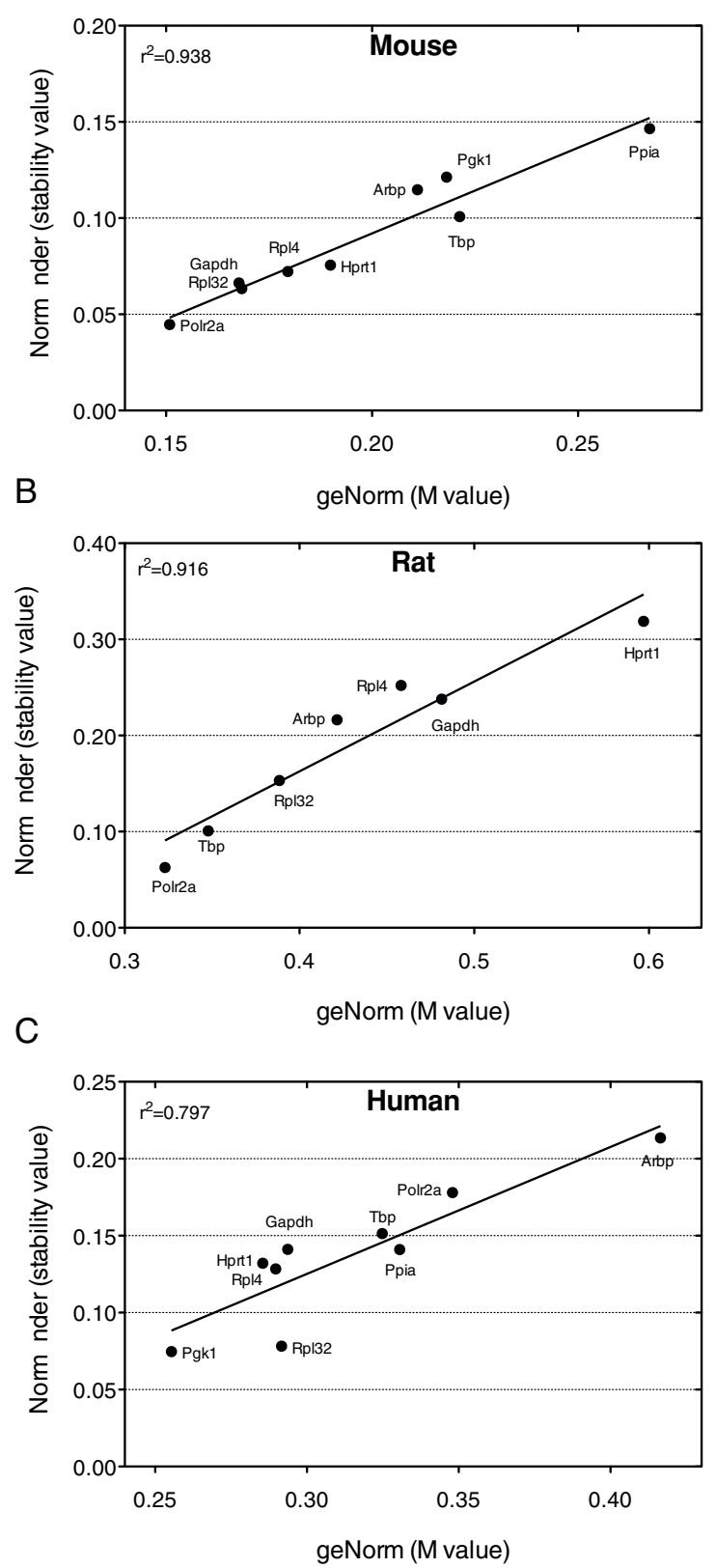

Figure 2 Comparison of geNorm and Normfinder reference gene variability. For each reference gene, the geNorm $M$ values and Normfinder stability values were calculated separately for each RT reaction $(n=3)$ and averaged. The correlations between stability values by both methods are shown for (A) mouse, (B) rat and (C) human samples.

stability rank order by the geNorm method (dataset 1 : Rpl32 < Tbp <Arbp <Rpl4 <Gapdh; dataset 2: Tbp $<$ Rpl32 $<$ Arbp $<$ Rpl4 $<$ Gapdh). Analysis by the Normfinder method yielded also near-identical rank orders (dataset 1: Rpl32 $\leq$ Tbp $<$ Arb $<$ Rpl4 $<$ Gapdh versus dataset 2: $T b p \leq R p l 32<R p l 4<$ Arbp $<$ Gapdh). 
Table 2 The most stable reference genes in mouse, rat and human myocardium

\begin{tabular}{llll}
\hline Rank & Mouse & Rat & Human \\
\hline 1 & Rpl32 & Polr2a & Rpl32 \\
2 & Gapdh & Rpl32 & Pgk1 \\
3 & Polr2a & Tbp & Ppia \\
4 & Rpl4 & Arbp & Rpl4 \\
\hline
\end{tabular}

Reference gene rank was calculated from the combined stability results of geNorm, Normfinder and variance component analysis methods for each species.

\section{Reference gene stability across developmental stages in rat myocardium}

Fetal and neonatal cardiomyocyte preparations are used as model systems for hypertrophy responses and induction of the fetal gene program. The stability of a subset of reference genes was tested across a range of late fetal and neonatal stages and in normal de novo adult rat hearts. This subset was analyzed by geNorm across developmental stage (M-values in parentheses), resulting in the final ranking: Rpl4 (0.275), Arbp (0.289), Tbp (0.355), Rpl32 (0.364) and Gapdh (0.421). A pronounced shift in the Normfinder stability values, in particular for Gapdh, was observed in the transition from neonatal to adult myocardium (Figure 3A). Although none on the tested genes were very stable, Normfinder considered Rpl4 as the most stable reference gene across developmental stage, in agreement with the geNorm results.

The impact of normalization to a single reference gene with low (Rpl4, Arbp and Rpl32) or high (Gapdh) variability was evaluated in fetal, neonatal and adult stages (Figure 3B). Normalization of the serotonin transporter 5-HTT (Slc6a4, SERT) mRNA to Rpl4 suggested that
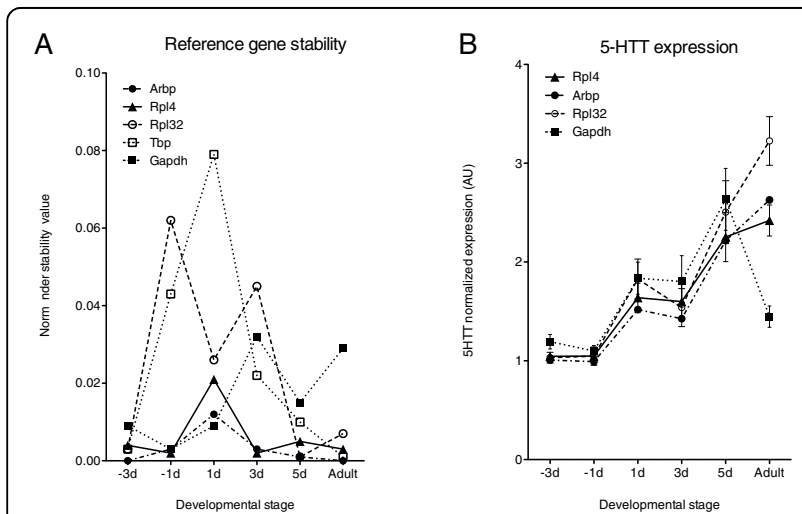

Figure 3 Reference gene stability and normalization effects in fetal, neonatal and adult rat myocardium. A) The Normfinder stability values were calculated from the relative mRNA quantities of the indicated genes in myocardial samples from rat late fetal $(-3 d$ and $-1 d$ ), neonatal (1d, 3d and 5d) and adult (age 113 days) developmental stages. B) The relative abundance of the serotonin transporter 5-HTT (S/c6a4) mRNA across developmental stages normalized to Rp/4, Arbp, Rp/32 and Gapdh. AU, Arbitrary units.
5-HTT expression increased with developmental stage. In contrast, normalization of 5-HTT to Gapdh indicated only a transient increase in 5-HTT expression.

\section{Discussion}

We have identified several reference genes as alternatives to Gapdh and $18 S$ for use in gene expression quantification in heart failure studies. The most stable reference genes were Rpl32, Gapdh and Polr $2 a$ in mouse post-infarction heart failure, Polr $2 a, R p l 32$ and $T b p$ in rat post-infarction heart failure and Rpl32 and $P g k 1$ in human heart failure (ischemic disease and cardiomyopathy). The overall most stable reference genes across all three species were Rpl32 and Polr $2 a$. In rat myocardium, Rpl4 was the most stable reference gene across developmental stages.

It is generally accepted that the best normalization strategy would be to calculate the geometric mean of several reference genes [13]. However, this is not always feasible with limited amounts of tissue. Several of the reference gene candidates identified in this study should be sufficiently stable for single-gene normalization of gene expression data when necessary. We show that Gapdh is not suitable as a reference gene in human failing myocardium. A recent study using human heart failure microarray data also reached a similar conclusion [12].

Gene expression studies using fetal and neonatal heart material often use single reference gene normalization methods. Single reference gene normalization across developmental stages may be difficult because of the wide variation in expression at different developmental stages [14]. We show here a marked shift in the expression stability of several reference genes in the transition from neonatal to adult rat myocardium. This effect was particularly pronounced for Gapdh, which would highly influence the interpretation of results. We found that Rpl4 and Rpl32 were better reference gene candidates across developmental stages in rat myocardium.

To explore the significance of normalization to different reference genes we analyzed the expression of the serotonin 5-HT transporter (5-HTT) during fetal and neonatal development as well as in adult heart. We have previously demonstrated that the mRNA encoding the $5-\mathrm{HT}_{4}$ serotonin receptor is significantly upregulated in heart failure $[11,15,16]$ and late fetal and neonatal development (T. Brattelid, unpublished observations). Serotonin plays an important role in cardiac development [17], and the 5-HT transporter can indirectly modulate the 5$\mathrm{HT}_{4}$ response by regulating the extracellular 5-HT level in cardiac muscle. Although the expression profile of 5-HTT in late fetal and neonatal heart seems to be independent of the reference gene used, the estimated 5-HTT expression in the adult heart differs significantly 
with the choice of reference gene (Figure 3B). Rpl32 and Gapdh represent the extreme in each direction in stability, whereas Rpl4 is the most stable reference gene when comparing fetal, neonatal and adult heart tissue.

In the datasets for mouse, rat dataset 1 and human reference genes, we originally included a test set of 4 commonly queried transcripts in the heart failure literature (Apt2a2, Pln, Slc8a1, Nppa) to test the impact of choice of reference genes on gene expression ratios (MI/ Sham or Failing/Donor). In contrast to the fetal and neonatal rat data, the ratios and statistical significance in the adult datasets were not markedly affected by choosing between the single most stable gene, the three most stable genes, Rpl32 alone or Gapdh alone in each species (data not shown). This was due to the very small differences in the stability between the most stable reference genes in our datasets.

We found a surprising discrepancy in the variability score for Polr2a between rodent and human datasets by both the geNorm and Normfinder algorithms, being low in mouse and rat (Figure 2), but high in the human dataset. In contrast, the variance component analysis indicated that human Polr $2 a$ was quite stable, and the Polr $2 a$ expression levels were very similar in the donor and failing human myocardial samples (Figure 1C). We therefore examined whether this could be due to differences in the mathematical algorithms. geNorm uses pairwise comparisons of genes and assumes that the ratio between the expression values of two stable reference genes should be approximately equal in all experimental samples [13]. A gene is regarded as less stable if the pattern of variation between samples differs from the pattern observed for the majority of candidate genes, assuming that the majority are in average stable. Normfinder uses analysis of variance on log-transformed expression values, and all genes and samples are used simultaneously to estimate expected expression values [18]. A stable gene is expected to deviate only modestly from these estimates. A stability value is computed based on intra- and inter-group variations, where calculation of the latter assumes equal average expression of the genes in the groups. Thus, although in a different way from geNorm, Normfinder also assumes good "average" behavior of the test genes. In the human myocardial samples, the donor hearts tended to have higher relative quantities than failing hearts for most of the tested genes (Figure 1C). Polr2a expression was very similar in the donor and failing groups, thereby deviating from the majority. Therefore, both geNorm and Normfinder classify Polr2a as less stable. In contrast, the variance component model considers the small difference between groups as an advantage. In light of these considerations, we chose to include both human Polr $2 a$ and rat Gapdh as satisfactory reference genes. A recent report investigating gene expression variation during the estrus cycle in female rats also discussed the potential shortcomings of geNorm and Normfinder and used similar methods to the variance component model used in our study [19].

Excellent quality of total RNA is vital for obtaining reliable quantification results [20-23]. The RNA sample quality was comprehensively evaluated. Total RNA quality is traditionally estimated by the $260 \mathrm{~nm} / 280 \mathrm{~nm} O$. D. ratio, even though this method has several shortcomings [21]. All samples included in the study were regarded as high quality using $260 \mathrm{~nm} / 280 \mathrm{~nm}$ O.D. ratio values. In contrast to the high $28 S / 18 S$ ratios $(>2)$ usually obtained in cell lines, we found a low ratio (average 1.3) in myocardial tissue from all three species. Studies in human tissues have shown poor correlation between the $28 \mathrm{~S} / 18 \mathrm{~S}$ ratio and RNA sample quality $[20,21,23,24]$. The RNA integrity number (RIN) is the most recent qualitative indicator of total RNA sample quality $[20,21,24,25]$. We found that the RIN values for rat and mouse myocardial total RNA (average 8.0) were consistent with values from solid tissues [20,21]. However, the RIN values for the human myocardial samples were consistently lower and the variation in the RTqPCR data much larger than for mouse and rat, in particular for the failing hearts. This may be due to variable states of severely failing human myocardial tissue or to differences in the human sample harvesting time compared to the rapid handling of rodent myocardial samples. Even though we obtained very similar results for reference gene stability with rat datasets 1 and 2, which had considerable differences in preparation and $\mathrm{RT}$ priming methods, we cannot exclude that the difference in results between the human and rodent datasets may be due to differences in RNA isolation, cDNA priming methods or choice of reverse transcriptase enzymes $[22,26]$.

In our comparison of the two independent datasets from rat Sham and post-MI myocardium, we found that the stability of the selected reference genes was independent of sample processing and cDNA priming method, thus strengthening our findings. We also found that the biological variation contributed the most to the overall quantification variability rather than technical steps such as reverse transcription and PCR amplification reactions. Thus, for myocardial samples, increasing the biological sample size rather than number of RT reaction technical replicates is a key factor for increasing the reliability of gene expression analysis.

\section{Conclusions}

In the set of tested reference genes, the most stable reference genes were Rpl32, Gapdh and Polr2a in mouse post-infarction heart failure, Polr $2 a$, Rpl32 and 
Tbp in rat post-infarction heart failure and $R p l 32$ and $P g k 1$ in human heart failure (ischemic disease and cardiomyopathy). The overall most stable reference genes across all three species were Rpl32 and Polr2a. In rat myocardium, Rpl4 was the most stable reference gene across developmental stages. These reference genes should be regarded as good a priori candidates, but validation of expression stability in each particular experimental setting is recommended.

\section{Methods}

\section{Selection of candidate reference genes}

Candidate reference genes were selected based on previous use in Northern blots and competitive RT-PCR and RT-qPCR studies in the literature: acidic ribosomal phosphoprotein P0 $(A r b p)$, ribosomal protein L32 (Rpl32), ribosomal protein L4 (Rpl4), TATA-box binding protein $(T b p)$, RNA polymerase II alpha subunit (Polr2a), hypoxanthine guanine phosphoribosyl transferase (Hprt1), phosphoglycerate kinase 1 (Pgk1) and cyclophilin A (peptidyl prolyl isomerase A, Ppia), glyceraldehyde-3-phosphate dehydrogenase (Gapdh) and $18 S$ ribosomal RNA.

\section{Tissue material and total RNA sample sets}

The B6/J mouse total RNA sample set was generated in this study. Rat and human myocardial total RNA sample sets were used previously in other studies in Wistar rats (adult dataset 1[27], adult dataset 2 [11]), fetal and neonatal rat material (Brattelid et al, in preparation), and humans [15]. Random samples that fulfilled basic "good quality" OD 260/280 ratios (approximately 2.0) were chosen from each sample set. The RNA quality of these samples was reanalyzed more extensively in this study, including RIN profiling (Table 1). Samples sizes for datasets were as follows: mouse (Sham $\mathrm{n}=3$, MI $\mathrm{n}=3$ ), rat dataset 1 (Sham $\mathrm{n}=3$, MI $\mathrm{n}=3$ ), rat dataset 2 (Sham $n=6$, MI $n=6$ ) and human (Donor $n=4$, Failing $\mathrm{n}=6$ ).

Myocardial infarction (MI) in B6/J mice and Wistar rats was induced by ligating the left anterior descending coronary artery as described $[27,28]$. Age-matched Sham animals underwent the same operative procedure, but without ligating the artery. Mouse hearts were harvested after 1 week, whereas rat hearts were harvested after 6 weeks. In the original studies, criteria indicative of congestive heart failure (significantly increased left ventricular end-diastolic pressure, increased lung weight and increased lung weight/body weight ratios) were used to include mice and rats in the MI groups [28,29]. In postMI hearts, the infarct area and border zone were removed and the remaining viable left ventricular wall and septum were harvested. In Sham and de novo (control) animals, the left ventricular wall and septum were harvested. Total RNA from a second set of rat left ventricles from 6-week post-MI rat hearts, age-matched Sham hearts and de novo animals [11], were used to test whether the combined differences in tissue storage, RNA isolation and cDNA priming methods would affect reference gene stability results (rat data set 2).

Fetal rat hearts were harvested from embryos removed under $2 \%$ isoflurane anesthesia at day $3(n=6)$ and day $1(n=5)$ before the expected term. Neonatal rat hearts were harvested at $1(n=10), 3(n=6)$ and $5(n=6)$ days after birth. Atria were removed and ventricles from each litter were pooled. All animals were subjected to approved protocols in accordance with the Norwegian National Committee for Animal Welfare, conforming to the European Convention for the protection of Vertebrate animals used for Experimental and other Scientific Purposes (Council of Europe no. 123, Strasbourg 1985). Human samples were taken from left ventricular trabeculae from non-failing donor and failing hearts. The failing hearts were from patients undergoing heart transplantation for end-stage heart failure, resulting from ischemic heart disease or dilated cardiomyopathy. Samples were obtained under ethical approval \#S01025 (Oslo University Hospital Rikshospitalet, Oslo, Norway) conforming to the Declaration of Helsinki. Mouse hearts and rat hearts for dataset 1 and human samples were immediately frozen in liquid nitrogen. Adult rat hearts for dataset 2, fetal, and neonatal rat hearts were submerged and stored in RNAlater ${ }^{\mathrm{TM}}$ (Applied Biosystems/ Ambion, Austin, TX, USA).

Mouse total RNA was isolated from left ventricular myocardium using a tissue homogenizer (Polytron, Kinemetica AG, Luzern, Switzerland) and SV total RNA columns as described by the manufacturer (Promega, Madison, WI, USA). Adult rat total RNA for dataset 1 was isolated from left ventricular myocardium [27] using a tissue homogenizer and the phenol/chloroform method as included in the Atlas ${ }^{\mathrm{TM}}$ Pure Total RNA Labeling kit (Clontech Laboratories Inc. Mountain View, CA, USA). Adult rat left ventricular total RNA for dataset 2 , fetal and neonatal RNA samples, were obtained by washing the RNAlater-conserved tissue in sterile $0.9 \%$ $\mathrm{NaCl}$, followed by homogenization in $1.5 \mathrm{ml}$ Trizol by mill grinding (MM301, Retsch GmbH, Haan, Germany) with ceramic beads at $30 \mathrm{~Hz}$, and isolatation of total RNA by the Trizol method [11]. Total RNA from human hearts was isolated by pulverization in liquid $\mathrm{N}_{2}$, homogenization with a tissue homogenizer and RNeasy columns (Qiagen Hilden, Germany) [15].: Mouse and rat dataset 1 total RNA samples were treated with DNase provided in the the RNA isolation kits, and human total RNA samples were treated with DNase I from Invitrogen (Carlsbad, CA, USA) as described by the manufacturers. 
Table 3 RT-qPCR assay information

\begin{tabular}{|c|c|c|c|c|c|c|}
\hline $\begin{array}{l}\text { Gene } \\
\text { Symbol }\end{array}$ & Genbank ID & Assay information & $\begin{array}{l}\text { Primer location on } \\
\text { Refseq }\end{array}$ & $\begin{array}{l}\text { Amplicon } \\
\text { (bp) }\end{array}$ & $\begin{array}{l}\text { Target } \\
\text { exons }\end{array}$ & $\mathrm{E}$ \\
\hline \multicolumn{7}{|l|}{ Mouse genes } \\
\hline Rplpo (Arbp) & NM_007475 & AB ID Mm00725448_s1 & & 124 & 7 & 0.86 \\
\hline \multirow[t]{3}{*}{ Rp/32 } & NM_172086 & F: CAC CAG TCA GAC CGA TAT GTG AAA A & $118-142$ & 64 & $2-3$ & 0.92 \\
\hline & & R: TGT TGT CAA TGC CTC TGG GTT T & $160-181$ & & & \\
\hline & & P: CCG CCA GTT TCG CTT AA & $143-159$ & & & \\
\hline \multirow[t]{3}{*}{ Rp/4 } & NM_024212 & F: GGT GGT TGA AGA TAA GGT TGA AGG T & $500-524$ & 71 & 5 & 0.88 \\
\hline & & R: CTT TGA GTT TCT TGA GCA GCT GAA & $547-570$ & & & \\
\hline & & P: CAG CCT CCT TGG TCT TC & $530-546$ & & & \\
\hline Tbp & NM_013684 & AB ID Mm00446973_m1 & & 73 & $4-5$ & 0.78 \\
\hline \multirow[t]{3}{*}{ Polrza } & NM_009089 & F: CTT TGA GGA AAC GGT GGA TGT C & $4293-4314$ & 67 & 26 & 0.94 \\
\hline & & R: TCC CTT CAT CGG GTC ACT CT & $4340-4359$ & & & \\
\hline & & P: ATG TGC TGC TGC TTC C & $4320-4335$ & & & \\
\hline Hprt1 & NM_013556 & AB ID Mm00446968_m1 & & 65 & $6-7$ & 0.84 \\
\hline Gapdh & NM_008084 & AB ID Mm99999915_g1 & & 107 & $2-3$ & 0.79 \\
\hline Pgk1 & NM_008828 & AB ID Mm00435617_m1 & & 137 & $5-6$ & 0.77 \\
\hline \multirow[t]{3}{*}{ Ppia } & NM_008907 & F: GCA CTG CCA AGA CTG AAT GG & $385-404$ & 63 & $4-5$ & 0.81 \\
\hline & & R: TGC CTT CTT TCA CCT TCC CAA A & $426-447$ & & & \\
\hline & & P: CTG GAT GGC AAG CAT G & $405-420$ & & & \\
\hline Atp2a2 & NM_009722 & AB ID Mm00437634_m1 & & 59 & $20-21$ & 0.87 \\
\hline Pln & NM_023129 & AB ID Mm00452263_m1 & & 71 & $1-2$ & 0.83 \\
\hline S/c8a1 (Ncx1) & NM_011406 & AB ID Mm00441524_m1 & & 72 & $10-11$ & 0.78 \\
\hline \multirow[t]{3}{*}{ Nppa } & NM_008725 & F: GTA CAG TGC GGT GTC CAA CA & $170-189$ & & $1-2$ & 0.80 \\
\hline & & R: CTC ATC TTC TAC CGG CAT CTT CTC & $231-254$ & & & \\
\hline & & P: AAG AAC CTG CTA GAC CAC C & $207-225$ & & & \\
\hline
\end{tabular}

\section{Rat genes}

Arbp (Rplpo)

Rp/32

Rpl4

NM_022402

AB ID Rn00821065_g1

NM_013226 AB ID Rn00820748_g1

Top

NM_022510 AB ID Rn00821091_g1

NM_001004198

F: CCT CTG AGA GCT CTG GGA TTG TA

R: GCC AAG ATT CAC GGT GGA TAC A

P: CCA CAG CTC CAA AAT A

Polr2a

XM_343922

F: CGT ATC CGC ATC ATG AAC AGT GA

R: TCA TCC ATC TTA TCC ACC ACC TCT T

P: CCT CCT CCT GCA TCT TG

Hprt1 NM_012583 AB ID Rn01527838_g1

5-HTT (SIC6a4) NM_013034 F: GTC ATC TGC ATC CCT ACC TAT ATC ATT

R: GTG GGT GTT TCA GGA GTG ATA CTT T

P: AAT AAT CCG CTC CTT AAG TGT CCC CGG AGT

$\begin{array}{lll}\text { Gapdh } & \text { NM_017008 } & \text { AB ID Rn99999916_s1 } \\ \text { Atp2a2 } & \text { NM_017290 } & \text { AB ID Rn00568762_m1 } \\ \text { PIn } & \text { NM_022707 } & \text { AB ID Rn01434045_m1 } \\ \text { Slc8a1 (Ncx1) } & \text { NM_019268 } & \text { AB ID Rn00570527_m1 } \\ \text { Nppa } & \text { NM_012612 } & \text { AB ID Rn00561661_m1 }\end{array}$

Nppa

NM_012612

AB ID Rn00561661_m1

Human genes

Rplp0 (Arbp) NM_001002 AB ID Hs99999902_m1

Rpl32 NM_000994

F: CAC CAG TCA GAC CGA TAT GTC AAA A

R: TGT TGT CAA TGC CTC TGG GTT T

P: CCG CCA GTT ACG CTT AA

Rp/4

NM_000968

F: CAG CAC TGG TCA TGT CTA AAG GT

R: AGC CTT CAA CTT TAT CTT CAA CTA CCA AA

P: CAT CGT ATT GAG GAA GTT C

AB ID Hs00427620_m1
161-185

203-224

666-688

706-727

689-704

4181-4203

4227-4251

4210-4226

1863-1889

1936-1960

1905-1934

\section{6-202}

457-479

537-509

480-498

$\begin{array}{lll}97 & 1-2 & 0.90 \\ 72 & 1 & 0.80 \\ 82 & 5-6 & 0.84 \\ 62 & 3-4 & 1.10\end{array}$

71

22-24

0.92

\begin{tabular}{lll}
100 & $4-5$ & 0.86 \\
98 & $15-16$ & 0.76 \\
& & \\
& & \\
87 & 3 & 0.93 \\
83 & $3-4$ & 0.91 \\
59 & $1-2$ & 0,87 \\
115 & $5-6$ & 0,88 \\
58 & $2-3$ & 0.96 \\
\hline
\end{tabular}

$\begin{array}{lll}105 & 3 & 0.85\end{array}$

$\begin{array}{lll}64 & 2-3 & 0.93\end{array}$

81

4-5

0.93

91 
Table 3: RT-qPCR assay information (Continued)

\begin{tabular}{|c|c|c|c|c|c|}
\hline Polrza & NM_000937 & AB ID Hs00172187_m1 & 61 & $1-2$ & 0.87 \\
\hline Hprt1 & NM_000194 & AB ID Hs00355752_m1 & $\mathrm{N} / \mathrm{A}$ & $\mathrm{N} / \mathrm{A}$ & 0.74 \\
\hline Gapdh & NM_002046 & AB ID Hs99999905_m1 & 122 & 3 & 0.98 \\
\hline Pgk1 & NM_000291 & AB ID Hs99999906_m1 & 75 & $4-5$ & 0.74 \\
\hline Ppia & NM_021130 & AB ID Hs99999904_m1 & 98 & 4 & 0.75 \\
\hline Atp2a2 & NM_001681 & AB ID Hs00544877_m1 & 123 & $5-6$ & 0.90 \\
\hline Pln & NM_002667 & AB ID Hs00160179_m1 & 98 & $1-2$ & 0.69 \\
\hline Slc8al (Ncx1) & NM_021097 & AB ID Hs00253432_m1 & 58 & $2-3$ & 0.83 \\
\hline Nppa & NM_006172 & AB ID Hs00383230_g1 & 105 & $1-2$ & 0.81 \\
\hline $18 \mathrm{~S}$ & X03205 & $\begin{array}{l}\text { Eukaryotic } 185 \text { endogenous control, part number } \\
4319413 \mathrm{E}\end{array}$ & 187 & N/A & 1.06 \\
\hline
\end{tabular}

All DNA sequences are in $5^{\prime}-3^{\prime}$ direction. $F$, forward primer; $R$, reverse primer, $P$, probe.

E, assay amplification efficiency; AB ID, Applied Biosystems hydrolysis probe (Taqman) Gene Expression Assay ID; Part number (Applied Biosystems). N/A, not available.

Pooled standard samples used to generate relative dilution curves for each species were prepared by mixing equal amounts of total RNA from 3 Sham and $3 \mathrm{MI}$ hearts (mouse, rat), or 3 non-failing and 3 failing hearts (human), and used throughout the study.

\section{RNA quality control}

RNA concentrations were measured $(1.5 \mu \mathrm{l})$ in an ND1000 spectrophotometer (NanoDrop Technologies, Wilmington, DE, USA). Samples were quality checked using RNA 6000 Nano LabChips in a 2100 Bioanalyzer (Agilent Technologies, Santa Clara, CA, USA). The RNA integrity numbers (RIN) [25] were calculated by the instrument software. $18 S$ serial dilution curves were run for each sample, and the linearity of the curves was used to verify the absence of inhibitory substances.

\section{RT-qPCR quantification}

Mouse, rat (dataset 1), and human total RNA sample sets were reverse transcribed using random primers and TaqMan Reverse Transcription Reagents (P/N N8080234, Applied Biosystems, Foster City, CA, USA). Each RNA sample was reverse transcribed independently on three separate days. All species-specific gene expression assays were run on the same cDNA generated in each independent $\mathrm{RT}$ reaction, thus allowing direct comparison of the relative abundance of all the reference genes within each species. The second set of de novo, Sham and post-MI adult rat myocardium total RNA as well as fetal and neonatal rat total RNA $(5 \mu \mathrm{g})$ were oligo-dTprimed and transcribed with $400 \mathrm{U}$ Superscript III (Invitrogen) in a $40 \mu$ l volume.

PCR assays were TaqMan ${ }^{\circledR}$ Gene Expression Assays or Custom Gene Expression Assays (Applied Biosystems) (Table 3). All probes were labeled with 5'-FAM and 3'non-fluorescent quencher. Each PCR reaction contained $12.5 \mu \mathrm{l}$ TaqMan Universal PCR Mastermix ${ }^{\circledR}, 1.25 \mu \mathrm{l}$ assay stock $(20 \times)$, primers $(900 \mathrm{nM})$, probe $(250 \mathrm{nM})$ and cDNA in $25 \mu \mathrm{l}$ final volume. PCR amplifications were run in triplicates in 96-well plates with cycling parameters $2 \min 50^{\circ} \mathrm{C} ; 10 \min 95^{\circ} \mathrm{C} ; 40$ cycles of $5 \mathrm{~s}$ $95^{\circ} \mathrm{C}, 1 \mathrm{~min} 60^{\circ} \mathrm{C}$ in a 7700 (mouse) or a $7900 \mathrm{HT}$ (rat, human) Sequence Detection Instrument (Applied Biosystems). Assay performance was evaluated by serial dilution curves and amplification efficiencies calculated by the formula $E=10^{(1 / \text {-slope })}-1$ using the slope of the relative dilution curve generated by species-specific pooled standard samples (Table 3 ). The specificity of each assay was verified on $2 \%$ agarose gels. To avoid loss of low copy number cDNA species, carrier tRNA was added to maintain a constant total nucleic acid input in the PCR reactions. This reduced the standard curve variability at high dilutions and in quantification of low abundance transcripts (data not shown). Quantification of $18 S$ and specific mRNA transcripts were run at different cDNA input levels to accommodate the large difference in $18 \mathrm{~S}$ and mRNA abundance. For each biological sample, the baseline and threshold settings were identical for all RT runs for each gene-specific assay. Non-normalized gene expression values were calculated from species-specific standard sample serial dilution curves. The second set of control and post-MI adult rat myocardium total RNA as well as fetal and neonatal rat total RNA was analyzed using a subset of TaqMan Gene expression assays for comparison.

\section{Statistical analysis}

The mean assay coefficient of variation (CV, given in \%) per species was calculated by first calculating the $\mathrm{CV}$ of all data points for a given assay in a species, and then calculating the mean $\mathrm{CV}$ value for all assays within that species.

Reference gene expression variability was evaluated by geNorm [13] and Normfinder [18] analysis methods. 
Ratios were analyzed on the log scale to obtain approximately normally distributed observations (without outliers) and roughly equal variance across genes. Tests were two-sided, and $\mathrm{p}<0.05$ considered significant.

Mixed linear models were used to accommodate the nested experimental design and to estimate variance components and expression ratios with associated confidence intervals. Variance components included in the model were the RT reactions and the samples (nested within treatments), and with the triplicate PCR values with each run as the basic observation. We also used the sum of the variance components for the samples and the triplicates as an additional tool when evaluating gene expression stability. These types of models take into account the study design, but are limited as a general tool for evaluation of reference gene stability, because they are sensitive to large variations in total RNA quantity between samples.

\begin{abstract}
Acknowledgements
We gratefully acknowledge Alexandra Finsen for Sham and post-MI mouse hearts, Odd Geiran and Halfdan Aass at Oslo University Hospital Rikshospitalet, Oslo, Norway for the human heart tissue samples, and the Department of Medical Genetics, Oslo University Hospital Ullevål, for use of the ABI 7700 instrument. We also thank Cathrine Husberg, Kåre Olav Stensløkken, and William E. Louch for critical reading of the manuscript. Supported by The Research Council of Norway, The Norwegian Council on Cardiovascular Diseases, Anders Jahre's Foundation for the Promotion of Science, The Novo Nordisk Foundation, The Family Blix foundation, a University of Oslo EMBIO senior fellowship (KBA) and a Southeastern Norway Regional Health Authority senior fellowship (KBA).
\end{abstract}

\section{Author details}

'Institute for Experimental Medical Research, Oslo University Hospital Ullevål, Oslo, Norway. ${ }^{2}$ Department of Pharmacology, University of Oslo, Oslo, Norway. ${ }^{3}$ Center for Heart Failure Research, Faculty of Medicine, University of Oslo, Oslo, Norway. ${ }^{4}$ Department of Informatics, University of Oslo, Oslo, Norway. ${ }^{5}$ Current address: National Institute of Nutrition and Seafood Research, Bergen, Norway.

\section{Authors' contributions}

TB conceived the study, designed and performed experiments, analyzed data and drafted the manuscript. LHW participated in sample preparation, performed experiments and helped to draft the manuscript. FOL participated in study design, data analysis, provided funding and drafting of the manuscript. KL performed statistical analysis and drafted the manuscript. OMS participated in study design, provided funding and drafting of the manuscript. KBA conceived the study, designed and performed experiments, analyzed data and drafted the manuscript. All authors read and approved the final manuscript.

Received: 6 May 2009 Accepted: 23 March 2010

Published: 23 March 2010

\section{References}

1. Bustin SA, Benes V, Nolan T, Pfaffl MW: Quantitative real-time RT-PCR-a perspective. J Mol Endocrinol 2005, 34(3):597-601.

2. Ivell R: A question of faith - or the philosophy of RNA controls. J Endocrinol 1998, 159(2):197-200.

3. Bustin SA: Quantification of mRNA using real-time reverse transcription PCR (RT-PCR): trends and problems. J Mol Endocrinol 2002, 29(1):23-39.

4. Dheda K, Huggett JF, Chang JS, Kim LU, Bustin SA, Johnson MA, Rook GA, Zumla A: The implications of using an inappropriate reference gene for real-time reverse transcription PCR data normalization. Anal Biochem 2005, 344(1):141-143.

5. Hendriks-Balk MC, Michel MC, Alewijnse AE: Pitfalls in the normalization of real-time polymerase chain reaction data. Basic research in cardiology 2007, 102(3):195-197.

6. Seeland U, Selejan S, Engelhardt S, Muller P, Lohse MJ, Bohm M: Interstitial remodeling in beta1-adrenergic receptor transgenic mice. Basic research in cardiology 2007, 102(2):183-193.

7. Vinet $L$, Rouet-Benzineb P, Marniquet $X$, Pellegrin N, Mangin $L$, Louedec $L$, Samuel JL, Mercadier JJ: Chronic doxycycline exposure accelerates left ventricular hypertrophy and progression to heart failure in mice after thoracic aorta constriction. Am J Physiol Heart Circ Physiol 2008, 295(1): H352-360.

8. Schmechel A, Grimm M, El-Armouche A, Hoppner G, Schwoerer AP, Ehmke $H$, Eschenhagen T: Treatment with atorvastatin partially protects the rat heart from harmful catecholamine effects. Cardiovasc Res 2009, 82(1):100-106.

9. Winer J, Jung CK, Shackel I, Williams PM: Development and validation of real-time quantitative reverse transcriptase-polymerase chain reaction for monitoring gene expression in cardiac myocytes in vitro. Anal Biochem 1999, 270(1):41-49.

10. Kakinuma Y, Miyauchi T, Suzuki T, Yuki K, Murakoshi N, Goto K, Yamaguchi I: Enhancement of glycolysis in cardiomyocytes elevates endothelin-1 expression through the transcriptional factor hypoxia-inducible factor-1 alpha. Clin Sci (Lond) 2002, 103(Suppl 48):210S-214S.

11. Brattelid T, Tveit K, Birkeland JA, Sjaastad I, Qvigstad E, Krobert KA, Hussain Rl, Skomedal T, Osnes JB, Levy FO: Expression of mRNA encoding $G$ protein-coupled receptors involved in congestive heart failure-a quantitative RT-PCR study and the question of normalisation. Basic research in cardiology 2007, 102(3):198-208.

12. Pilbrow AP, Ellmers LJ, Black MA, Moravec CS, Sweet WE, Troughton RW, Richards AM, Frampton CM, Cameron VA: Genomic selection of reference genes for real-time PCR in human myocardium. BMC Med Genomics 2008, 1:64.

13. Vandesompele J, De Preter K, Pattyn F, Poppe B, Van Roy N, De Paepe A, Speleman F: Accurate normalization of real-time quantitative RT-PCR data by geometric averaging of multiple internal control genes. Genome Biol 2002, 3(7):RESEARCH0034.

14. Cai JH, Deng S, Kumpf SW, Lee PA, Zagouras P, Ryan A, Gallagher DS: Validation of rat reference genes for improved quantitative gene expression analysis using low density arrays. Biotechniques 2007, 42(4):503-512.

15. Brattelid T, Qvigstad E, Lynham JA, Molenaar P, Aass H, Geiran O, Skomedal T, Osnes JB, Levy FO, Kaumann AJ: Functional serotonin 5-HT4 receptors in porcine and human ventricular myocardium with increased 5-HT4 mRNA in heart failure. Naunyn Schmiedebergs Arch Pharmacol 2004, 370(3):157-166.

16. Qvigstad E, Brattelid T, Sjaastad I, Andressen KW, Krobert KA, Birkeland JA, Sejersted OM, Kaumann AJ, Skomedal T, Osnes JB, et al: Appearance of a ventricular 5-HT4 receptor-mediated inotropic response to serotonin in heart failure. Cardiovasc Res 2005, 65(4):869-878.

17. Sari Y, Zhou FC: Serotonin and its transporter on proliferation of fetal heart cells. Int J Dev Neurosci 2003, 21(8):417-424.

18. Andersen $C L$, Jensen $J L$, Orntoft TF: Normalization of real-time quantitative reverse transcription-PCR data: a model-based variance estimation approach to identify genes suited for normalization, applied to bladder and colon cancer data sets. Cancer Res 2004, 64(15):5245-5250.

19. Schirman-Hildesheim TD, Bar T, Ben-Aroya N, Koch Y: Differential gonadotropin-releasing hormone $(\mathrm{GnRH})$ and $\mathrm{GnRH}$ receptor messenger ribonucleic acid expression patterns in different tissues of the female rat across the estrous cycle. Endocrinology 2005, 146(8):3401-3408.

20. Auer H, Lyianarachchi S, Newsom D, Klisovic MI, Marcucci G, Kornacker K: Chipping away at the chip bias: RNA degradation in microarray analysis. Nat Genet 2003, 35(4):292-293.

21. Imbeaud S, Graudens E, Boulanger V, Barlet X, Zaborski P, Eveno E, Mueller $\mathrm{O}$, Schroeder A, Auffray C: Towards standardization of RNA quality assessment using user-independent classifiers of microcapillary electrophoresis traces. Nucleic Acids Res 2005, 33(6):e56.

22. Perez-Novo CA, Claeys C, Speleman F, Van Cauwenberge P, Bachert C, Vandesompele J: Impact of RNA quality on reference gene expression stability. Biotechniques 2005, 39(1), 52, 54, 56. 
23. Copois V, Bibeau F, Bascoul-Mollevi C, Salvetat N, Chalbos P, Bareil C, Candeil L, Fraslon C, Conseiller E, Granci V, et al: Impact of RNA degradation on gene expression profiles: assessment of different methods to reliably determine RNA quality. J Biotechnol 2007, 127(4):549-559.

24. Dumur Cl, Nasim S, Best AM, Archer KJ, Ladd AC, Mas VR, Wilkinson DS, Garrett CT, Ferreira-Gonzalez A: Evaluation of quality-control criteria for microarray gene expression analysis. Clin Chem 2004, 50(11):1994-2002.

25. Schroeder A, Mueller O, Stocker S, Salowsky R, Leiber M, Gassmann M, Lightfoot S, Menzel W, Granzow M, Ragg T: The RIN: an RNA integrity number for assigning integrity values to RNA measurements. BMC molecular biology 2006, 7:3.

26. Ståhlberg A, Kubista M, Pfaffl M: Comparison of reverse transcriptases in gene expression analysis. Clin Chem 2004, 50(9):1678-1680.

27. Andersson KB, Florholmen G, Winer KH, Tønnessen T, Christensen G: Regulation of neuronal type genes in congestive heart failure rats. Acto Physiologica 2005, 186(1):17-27.

28. Finsen AV, Christensen G, Sjaastad I: Echocardiographic parameters discriminating myocardial infarction with pulmonary congestion from myocardial infarction without congestion in the mouse. J Appl Physiol 2005, 98(2):680-689.

29. Sjaastad I, Sejersted OM, llebekk A, Bjørnerheim R: Echocardiographic criteria for detection of postinfarction congestive heart failure in rats. J Appl Physiol 2000, 89(4):1445-1454.

doi:10.1186/1471-2199-11-22

Cite this article as: Brattelid et al:: Reference gene alternatives to Gapdh in rodent and human heart failure gene expression studies. $B M C$

Molecular Biology 2010 11:22.

\section{Submit your next manuscript to BioMed Central and take full advantage of:}

- Convenient online submission

- Thorough peer review

- No space constraints or color figure charges

- Immediate publication on acceptance

- Inclusion in PubMed, CAS, Scopus and Google Scholar

- Research which is freely available for redistribution

Submit your manuscript at www.biomedcentral.com/submit 